Center for Research on Economic and Social Theory

and

Department of Economics

Working Paper Series

Coase, Competition, and Compensation

Hal R. Varian

May, 1993

Number 93-15
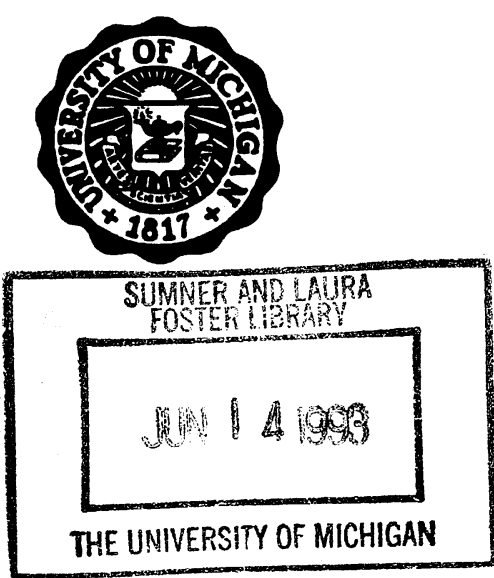

DEPARTMENT OF ECONOMICS

University of Michigan

Ann Arbor, Michigan 48109-1220 



\section{Coase, Competition, and Compensation}

$$
\text { by }
$$

\section{Hal R. Varian}

University of Michigan

\section{February 1992}

Current version: May 4, 1993

\begin{abstract}
I show that the Pigovian solution to a simple externalities problem and a particular Coasian solution can be viewed as competitive equilibria from different initial endowments. I also describe the "compensation mechanism," a mechanism that implements either the Coasian or Pigovian solution as the outcome of an economically natural bargaining game.
\end{abstract}

Keywords. Coase, Pigou, externalities, bargaining, competitive equilibrium

Address. Hal R. Varian, Department of Economics, University of Michigan, Ann Arbor, MI 48109-1220. E-mail: Hal . Varian@umich. edu
Coase (1960) thought that his analysis of social costs was very different from that of Pigou (1920). Indeed in Coase (1988), page 20-30, he argues that Pigou's viewpoint dominates the entire economics profession, and that Coase's viewpoint has been widely misunderstood. I see many merits in the Coasian analysis of externalities, but I do not agree that it is so different from the analysis of Pigou-or at least the way that modern economic analysis understands Pigou.

In this paper I examine the Pigovian and Coasian treatment of the simplest possible externalities problem, and show that the analyses come down to essentially the same thing, at least in a world with no transactions cost. I then go on to suggest how a particular mechanism might be used to implement either the Coasian or the Pigovian solution to an externalities problem.

\section{A simple externalities problem}

Let us consider a simple externalities problem from the viewpoints of Coase and Pigou. Agent 1 chooses an activity level $x$ to maximize his utility function $u(x)+m_{1}$, which we take to be strictly increasing and strictly concave in the action $x$. The good denoted by $m_{1}$ is a numeraire good that we can think of as "money" held by agent 1 . Agent 2 has a utility function $m_{2}-c(x)$ which we take to be strictly increasing and strictly convex in $x$; $m_{2}$ is money held by agent 2 . We assume that there is some initial endowment of money, $\left(\bar{m}_{1}, \bar{m}_{2}\right)$, and that $u(0)=c(0)=0$.

In one interpretation of this model $x$ is the level of production of some good, $u(x)$ is the profit of firm 1 , and $c(x)$ is the cost born by firm 2 due to a production externality from firm 1. But this is not the only interpretation. For example, $x$ could be a purely

This work was supported by the National Science Foundation Grant SES-8800114. I wish to thank Julie Nelson for comments on an earlier draft. 
private good. In this interpretation, agent 1's utility is increasing in the amount of $x$ that he consumes, but it costs agent 2 something to produce $x$.

In the first interpretation it is natural to think of agent 1 as choosing the level of $x$; in the second case, it is natural to think of agent 2 as choosing the level of $x$ : at this level of abstraction there is no distinction between "externalites" and ordinary goods. However, for most of what follows we will use the externality terminology.

\section{No intervention compared to efficient production}

In the absence of any intervention, we assume that agent 1 will choose an action $x_{n}$ where $u^{\prime}\left(x_{n}\right)=0$ and the utilities of each of the agents will be given by $u\left(x_{n}\right)+\bar{m}_{1}$ and $\bar{m}_{2}-c\left(x_{n}\right)$. This outcome is to be compared to the efficient amount of the activity $x$ which is characterized by the equation $u^{\prime}\left(x_{e}\right)-c^{\prime}\left(x_{e}\right)=0$. It is trivial to show that $x_{e}<x_{n}$-the efficient level of activity is less than the no-intervention level.

It is important to observe that the efficient level of activity is associated with many different utility levels. In general the utility possibilities frontier $\left(U_{1}, U_{2}\right)$ will be described by equations of the form

$$
\begin{aligned}
U_{1} & =u\left(x_{e}\right)+m_{1} \\
U_{2} & =m_{2}-c\left(x_{e}\right) \\
m_{1}+m_{2} & =\bar{m}_{1}+\bar{m}_{2} .
\end{aligned}
$$

Due to the quasilinear utility functions, the level of the activity is determined entirely by efficiency considerations, but the distribution of money between the two agents is arbitrary. It is easy to see from these equations that the utility possibilities frontier is linear, as shown in Figure 1.

\section{Pigovian taxes}

Pigou (1920) suggested that an efficient outcome could be supported in this model by choosing a corrective tax $t=e^{\prime}\left(x_{e}\right)$. It is irrelevant from an efficiency point of view what is done with the revenues from the corrective tax, but in order to close the model we will give the revenues of the tax to agent 2 . This may be viewed as "compensation" for the externality. ${ }^{1}$

In the Pigovian framework agent 1 faces an optimization problem $\max _{x} u(x)-t x$ which leads to first-order conditions $u^{\prime}(x)=t=e^{\prime}\left(x_{e}\right)$. It is clear that $x=x_{e}$ satisfies this first-order condition. The utility levels associated with the Pigovian tax are

$$
\begin{aligned}
& U_{1}=u\left(x_{e}\right)-c^{\prime}\left(x_{e}\right) x_{e}+\bar{m}_{1} \\
& U_{2}=c^{\prime}\left(x_{e}\right) x_{e}-c\left(x_{e}\right)+\bar{m}_{2} .
\end{aligned}
$$

Note that the Pigovian solution makes agent 1 worse off than he would be in the nointervention outcome, since $x_{e}<x_{n}$ and $e^{\prime}\left(x_{e}\right)>0$. Agent 2 is better off than he would be in the no-intervention case since $x_{e}<x_{n}$ and since he is receiving the tax revenues as "compensation" for the externality.

\section{Coasian bargains}

Coase (1960) suggests that we should view the externality problem as a bargaining problem. If the no-intervention outcome is inefficient that means that there is some way to make both agents better off. Hence the "right" way to solve the externalities problem is to encourage the agents to find such a Pareto-improving action. The set of all Pareto efficient allocations that dominate the no-intervention allocation is described by the equations

$$
\begin{aligned}
U_{1} & =u\left(x_{e}\right)+m_{1} \geq u\left(x_{n}\right)+\bar{m}_{1} \\
U_{2} & =m_{2}-c\left(x_{e}\right) \geq \bar{m}_{2}-c\left(x_{n}\right) \\
m_{1}+m_{2} & =\bar{m}_{1}+\bar{m}_{2} .
\end{aligned}
$$

See Figure 1 for the utility levels associated with no intervention, Pigovian taxation, and the set of Coasian outcomes. Note that in the Coasian outcome both parties are better off than they are in no intervention, but in the Pigou case the agent that causes the externality is worse off and the "victim" of the externality is better off than in the no-intervention case.

\footnotetext{
${ }^{1}$ If we do not give agent 2 the tax revenues we can create another agent, the "government," to hold these
} revenues. 


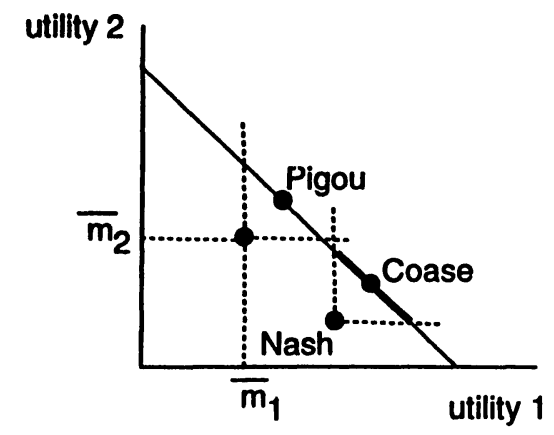

Figure 1. Utility possibilities frontier. The "Coase allocation" is the competitive equilibrium efficient allocation that Pareto dominates the no-intervention allocation. The Pigou allocation will be Pareto efficient but will not in general dominate the nointervention allocation.

\section{Competitive equilibrium}

There are many possible Coasian solutions that Pareto dominate the no-intervention outcome, but one that is of particular interest is the competitive equilibrium. Coase did not single out the competitive equilibrium as a particularly appropriate outcome, but given his strong support for market-based solutions to resource allocation problems it seems reasonable to identify this allocation as the "Coase allocation." Apparently Arrow (1970) was the first to explicitly point out that creating a market for an externality would, in principle, internalize the externality and yield an efficient allocation.

In the context of our simple model, a market would work like this. Each agent $i$ faces a price $p$ for the activity level $x$ and can demand or supply an amount $x_{i}$ of it. Each agent has some initial endowment of money, $\left(\bar{m}_{1}, \bar{m}_{2}\right)$, and there is an initial endowment of the activity $x_{1}\left(\bar{x}_{1}, \bar{x}_{2}\right)$. This initial endowment of the activity $x$ is to be interpreted as the outcome in the absence of trade. In Coase's view $\left(\bar{x}_{1}, \bar{x}_{2}\right)$ describes the initial property rights-the level of the activity to which the agents are legally entitled. We will explore various possible initial endowments below. In the particular problem that we are examining there can be only one level of production of $x$, so we can describe the initial endowment of $x$ by a single number $\bar{x}=\bar{x}_{1}=\bar{x}_{2}$.
Applying the standard general equilibrium model in this context, agent 1's utility maximization problem is

$$
\max _{x_{1}} u\left(x_{1}\right)+m_{1}
$$

such that $p x_{1}+m_{1}=p \bar{x}+\bar{m}_{1}$.

Assuming that $m_{1} \geq 0$, we can write

$$
\max _{x_{1}} u\left(x_{1}\right)+\bar{m}_{1}+p\left(\bar{x}-x_{1}\right)
$$

which yields first-order condition $u^{\prime}\left(x_{1}\right)=p$. Inverting this first-order condition gives us agent 1's desired supply of the activity $x$ as a function of its price.

Since $x$ is a bad for agent 2, it is natural to think of it as having a negative price for agent 2 , which we write as $-p$, where $p$ is taken to be positive. Using this convention agent 2's utility maximization problem is

$$
\begin{aligned}
\max _{x_{2}} & m_{2}-c\left(x_{2}\right) \\
& -p x_{2}+m_{2}=-p \bar{x}+\bar{m}_{2} .
\end{aligned}
$$

Again, assuming $m_{2}$ is positive, we can write this as

$$
\max _{x_{2}} p\left(x_{2}-\bar{x}\right)+\bar{m}_{2}-c\left(x_{2}\right)
$$

which has first-order conditions of $p=c^{\prime}\left(x_{2}\right)$.

The total demand for $x$ equals the total supply of $x$ when $x_{1}=x_{2}$--that is, when each agent agrees on the level of the externality. In this case the first-order conditions for each agent become $p_{c}=u^{\prime}(x)=c^{\prime}(x)$. This is the same first-order condition that characterizes the efficient amount of the externality $x_{e}$. Hence the utility distribution associated with the competitive solution will be

$$
\begin{aligned}
& U_{1}=u\left(x_{e}\right)-u^{\prime}\left(x_{e}\right)\left(x_{e}-\bar{x}\right)+\bar{m}_{1} \\
& U_{2}=-c\left(x_{e}\right)+c^{\prime}\left(x_{e}\right)\left(x_{e}-\bar{x}\right)+\bar{m}_{2} .
\end{aligned}
$$




\section{Endowments and property rights}

What are possible choices for the endowments? One plausible choice is the no-intervention allocation. In this case the endowment of activity level is $\bar{x}=x_{n}$. This means that there is no trade, the outcome will be $\left(x_{n}, \bar{m}_{1}\right)$ for agent 1 and $\left(x_{n}, \bar{m}_{2}\right)$ for agent 2 . In terms of property rights, agent 1 has the right to produce $x_{n}$ if he so chooses, and agent 2 has to consume $x_{n}$, like it or not.

The utility distribution associated with the competitive equilibrium from this endowment is

$$
\begin{aligned}
& U_{1}=u\left(x_{e}\right)-u^{\prime}\left(x_{e}\right)\left(x_{e}-x_{n}\right)+\bar{m}_{1} \\
& U_{2}=-c\left(x_{e}\right)+c^{\prime}\left(x_{e}\right)\left(x_{e}-x_{n}\right)+\bar{m}_{2} .
\end{aligned}
$$

Since $x_{e}<x_{n}$, agent 1 is receiving a payment from agent 2 to reduce the level of the externality.

We know from the standard considerations that the competitive equilibrium from this endowment is Pareto efficient and at least as desirable to each agent as the initial endowment-which, in this case, is the no-intervention allocation. It is immediate that each agent is at least as well off at this efficient allocation as he would be at the nointervention point since each agent could choose $x_{1}=x_{2}=\bar{x}_{n}$ which would result in no intervention. We have labeled the competitive equilibrium from the no-intervention allocation "Coase" in Figure 1.

Another possible endowment is one where agent 1 has $\left(0, \bar{m}_{1}\right)$ and agent 2 has $\left(0, \bar{m}_{2}\right)$. This is the initial endowment where no production of $x$ is allowed in the absence of trade. In this case, agent 2 has the property rights in $x$--agent 2 can prevent agent 1 from producing $x$ if he so desires.

Substituting $\bar{x}_{1}=0$ and $\bar{x}_{2}=0$ into equation (3) we find that the competitive equilibrium from this initial endowment has utility levels

$$
\begin{aligned}
& U_{1}=u\left(x_{e}\right)-c^{\prime}\left(x_{e}\right) x_{e}-\bar{m}_{1} \\
& U_{2}=-c\left(x_{e}\right)+c^{\prime}\left(x_{e}\right) x_{e}+\bar{m}_{2} .
\end{aligned}
$$

In this allocation agent 1 pays agent 2 in order to be allowed to produce the efficient amount of output. Comparing (4) to (1) we see that this competitive equilibrium is same as the Pigovian allocation.
In summary: a Coasian solution to the externalities problem is one that Pareto dominates no-intervention. One such point is the competitive equilibrium from the endowment where the producer of the externality has all the property rights. A Pigovian solution to the externalities problem is a competitive equilibrium from the endowment where the victim of the externality has all the property rights. In the Arrow-Debreu model-a model with no frictions, information imperfections or other transactions costs--there is no reason to prefer one to the other.

\section{Taxation and compensation}

How does the analysis of the last section compare to what is said in Coase $(1960,1988)$ ? There are several points worth discussing.

The first point has to do with the nature of the tax system. Coase (1960) thought of taxes as payments based on total damages, whereas most observers seem to think of Pigovian taxes as being based on marginal damages. (See, for example, Baumol (1972).) The second point has to do with the payment of compensation. Coase (1960) argued that payment of damages would generally not be desirable since the damaged party would then not have correct incentives to avoid the damage. These two points turn out to be closely related; let us see how things work out in our simple model.

Suppose that agent 2's cost depend on some choice variable $y$--for example, where agent 2 chooses to reside. The no-intervention allocation would be described by the first-order conditions

$$
\begin{array}{r}
u_{x}\left(x_{n}\right)=0 \\
-c_{y}\left(x_{n}, y_{n}\right)=0 .
\end{array}
$$

The Pareto efficient choices of $x$ and $y$ are determined by

$$
\begin{array}{r}
u_{x}\left(x_{e}\right)-c_{x}\left(x_{e}, y_{e}\right)=0 \\
-c_{y}\left(x_{e}, y_{e}\right)=0 .
\end{array}
$$

Clearly, these will not in general be the same.

Suppose that agent 1 is required to fully compensate agent 2 for the damages he imposes, so that the agents' utilities are given by

$$
\begin{aligned}
& U_{1}(x)=u(x)-c(x, y) \\
& U_{2}(x)=c(x, y)-c(x, y) .
\end{aligned}
$$


Then agent 1 will choose $x$ so that $u_{x}(x)-c_{x}(x, y)=0$, but agent 2 is indifferent about his choice of $y$. One possible choice for agent 2 is the efficient choice, but that is just one choice among many. There is no reason to believe that an efficient outcome will result.

On the other hand, suppose that agent 1 faces the total costs he imposes on agent 2 , but agent 2 is not compensated for the externality. The first-order conditions are

$$
\begin{array}{r}
u_{x}(x)-c_{x}(x, y)=0 \\
c_{y}(x, y)=0,
\end{array}
$$

and it is easy to see that the efficient levels of $x$ and $y$ are the unique solutions to these equations under the usual strict curvature assumptions. There is no reason, in this model at least, for taxing agent 2 as Coase seemed to suggest in his discussion of "double taxation."

Suppose, instead of the nonlinear taxation based on total damages, that agent 1 is taxed at a rate $t=c_{x}\left(x_{e}, y_{e}\right)$, so that he wants to maximize $u(x)-t x$. We can either pay these tax revenues $t x$ to agent 2 or not. Either way the first-order conditions are

$$
\begin{array}{r}
u_{x}(x)-t=0 \\
c_{y}(x, y)=0 .
\end{array}
$$

When $t=c_{x}\left(x_{e}, t_{e}\right)$, these reduce to the first-order conditions describing the efficient allocation. In this model, at least, the payment of compensation based on marginal damages has no incentive effect.

But this will be true in general. We know from the second theorem of welfare economics there is some set of prices---which in general may involve personalized Lindahl prices--that will support any efficient allocation as a competitive equilibrium. Since the allocation is Pareto efficient, whatever is paid as a tax by some agent must be received as income by another, so that one agent's tax is another agent's compensation.

In general, someone has to receive the tax revenues collected from the Pigovian taxes if we want to maintain efficiency, and there is no reason why this shouldn't be the injured parties. Indeed, given the "natural" endowment property rights described above, the payment of compensation emerges as part of the competitive equilibrium.
Coase (1988), p 182, seems to agree with that the Pigovian solution in theory when he says "... I would not deny that Baumol's taxing system is conceivable and that if put into practice it would have the results he describes." However, he goes on to say "There is, as I see it, no way in which the information required for the Pigovian tax scheme could be collected." Baumol (1972) makes the same point, "We do not know how to calculate the required taxes and subsidies and we do not know how to approximate them by trial an error."

But we don't know how to achieve an efficient outcome via Coasian bargaining either! As my earlier analysis has shown, the Pigovian allocation is simply the competitive equilibrium that dominates a particular assignment of property rights while (a particular) Coasian allocation is the competitive equilibrium from another assignment of property rights. A mechanism that "solves" the Coasian bargaining problem could also solve the Pigovian problem. So far as the theory is concerned there both bargaining problems are equally difficult.

\section{Mechanisms to implement competitive equilibria}

In the previous sections we have seen that the competitive equilibrium resulting from the no-intervention endowment yields a Coasian solution to the externalities problem, and that the competitive equilibrium from the no-production endowment yields the Pigovian solution to the externalities problem.

The competitive equilibrium is, of course, only one allocation that Pareto dominates a given endowment; there are many others. One role that the legal system might play is to recommend mechanisms that can achieve efficient outcomes in such bargaining problems. I have in mind things like "one cuts, the other chooses," double oral auctions, second-bid auctions, Groves-Clarke taxes, and the like. The idea that one task of the legal system is to suggest mechanisms for settling bargains seems quite consistent with Coase. Indeed, in Coase (1988) he says, "Economic policy consists of choosing those legal rules, procedures, and administrative structures that will maximize the value of production." (page 28)

Economic theory, especially the theory of mechanism design and implementation, provides several examples of mechanisms that can achieve a Pareto dominating allocation. 
Nash (1953) suggested one mechanism that would achieve an efficient outcome in an abstract bargaining problem. Binmore and Dasgupta (1987) describes several other mechanism of this sort. Schweizer (1988) gives an example of a game whose subgame perfect equilibrium yields an efficient allocation in a setup very similar to the one we examine here.

Schweizer's game is essentially an ultimatum game. One agent proposes a division of the gains from trade, and the other agent can accept this contract or remain at the no-intervention allocation. Schweizer makes agent 2 the proposer in his model, but there is no reason why agent 1 couldn't be the proposer instead. Hence there are two possible "ultimatum contracts," depending on who gets to make the ultimatum. The "ultimatum allocations" are labeled $M_{\mathbf{1}}$ and $M_{\mathbf{2}}$ in Figure 1.

Schweizer's game achieves an efficient allocation, but imposes a very stark distributional tradeoff-one party gets all of the gains from trade. Presumably agents would devote resources to arguing over who got to move first, which could be quite costly from a social viewpoint. In practice, it is likely that one would want to adopt a bargaining mechanism that divided the gains from trade more evenly. For example, one could flip a coin to decide who got to move first, thereby equating the expected utilities of the agents. Or, if the problem is sufficiently symmetric, one agent could divide the gains from trade, and the other agent could choose which piece he wanted. ${ }^{2}$

The competitive equilibrium is a very attractive candidate for achieving a Pareto efficient allocation that dominates a particular initial endowment. We know from both practical experience and laboratory experiments that simple markets seem to do a pretty good job at achieving efficient outcomes. Furthermore, in a competitive equilibrium each agent typically shares in the gains from trade. ${ }^{3}$

However, Arrow (1970) pointed out that the market mechanism would be unlikely to achieve an efficient outcome in cases like the one discussed here since the market for 2 Schweizer (1988) proposed the ultimatum outcome only an example to show that there was a non-
cooperative bargaining solution that achieved an efficient outcome; he didn't advocate the adoption of this
mechanism. Schweizer (1989) examines the problem of how to choose a social choice mechanism.

3 Schmeidler and Vind (1974) show that the net trades in a competitive equilibrium satisfy an attractive no-envy condition: each agent prefers his net trade to that of the other agents. the externality would be very thin. In the example considered in this paper there is only one person on each side of the market and the assumption of competitive behavior is not plausible. This view is shared by many other authors, including Samuelson (1963), Samuelson (1967), and Schweizer (1988).

Arrow's observation has led many subsequent authors to reject the competitive equilibrium as a plausible mechanism to achieve efficient outcomes in such externalities problems. All of these authors seemed to have in mind the classical Arrow-Debreu conception of a market: many small agents who take prices as given. However, this is not the only framework that leads to competitive behavior. There is a vast literature on the problem of implementing a competitive equilibrium as the outcome of some game. Early contributions to this literature include Hurwicz (1979), Groves (1979), Maskin (1985) and Walker (1981). More recent surveys of this literature include Groves (1979), Groves and Ledyard (1987) and Moore (1991).

However, I think that it is safe to say that most of the mechanisms designed to implement competitive equilibrium are rather complex: they don't seem simple enough to be really practical. However, I have recently discovered another mechanism, which I call the compensation mechanism, that seems to be simple enough to possibly be practical in small-scale resource allocation problems.

A key insight in developing the compensation mechanism comes from the industrial organization literature. In the oligopoly literature one encounters the Bertrand model of duopoly which involves two identical price-setting firms. It is easy to show that the only equilibrium in such a duopoly involves price being set equal to marginal cost. The fact that you get a competitive outcome with only two firms is sometimes called the "Bertrand paradox." (See Tirole (1988).)

Despite this terminology, I don't think that the Bertrand paradox is so paradoxical. The real-world analog of the Bertrand model is a one-shot competitive bidding game. The consumers ask each firm to submit a sealed bid, with the understanding that the consumers will buy from the firm with the lowest bid. If the firms are not allowed to communicate, then it is not so uncommon for this sort of mechanism to result in prices that are reasonably close to marginal cost---after all, that's why sealed bidding is so popular. 
This observation suggests that the thinness of the market for externalities may not be an insurmountable problem if one makes the agents compete in setting prices. This central insight leads us to investigate price-setting mechanisms for internalizing externalities.

\section{The compensation mechanism}

In Varian (1989) I describe a simple price-setting mechanism, the compensation mechanism, whose subgame-perfect equilibrium is the competitive equilibrium. I show that the compensation mechanism works in a broad set of cases. Here I specialize this mechanism to the externalities example considered in this paper.

Bidding stage. Agents 1 and 2 simultaneously submit sealed bids for the price of the externality. Denote the bid of firm 1 by $p_{1}$ and the bid of firm 2 by $p_{2}$.

Choice stage. Agent 1 chooses $x$ and receives a payment $p_{2}[\bar{x}-x]-\left[p_{1}-p_{2}\right]^{2}$. Agent 2 makes a payment $p_{1}[\bar{x}-x]$.

Note the structure of the game. Agent 1 announces a price that agent 2 will have to pay if agent 2 wants the externality reduced. Agent 2 names a price that agent 1 will have to pay if he wants to increase the level of the externality. Agent 1 also faces a (presumably small) penalty if he names a price that is different from the price named by agent 2 . I claim that the unique subgame-perfect equilibrium in this game is for each agent to choose the price $p_{c}=u^{\prime}\left(x_{e}\right)=c^{\prime}\left(x_{e}\right)$. In this case the budget balances and we get exactly the competitive equilibrium outcome from the endowment $\left(\bar{x}, \bar{m}_{1}\right)$ and $\left(\bar{x}, \bar{m}_{2}\right)$.

Let us see how this works. In the choice stage of the game, agent 1 will choose $x\left(p_{2}\right)$ to satisfy

$$
u^{\prime}\left(x\left(p_{2}\right)\right)=p_{2} .
$$

Under standard assumptions, $x^{\prime}\left(p_{2}\right)<0$.

Note that the only place that $p_{1}$ enters agent 1 's utility function is in the quadratic penalty term. Agent 1 will want to make this penalty as small as possible, which means that he will set
The bidding stage for agent $\mathbf{2}$ is a bit more complex, since he has to recognize that his bid will affect agent 1's behavior in the choice stage, via the "reaction" function $x\left(p_{2}\right)$. Agent 2's will choose $p_{2}$ so as to induce an $x\left(p_{2}\right)$ that maximizes agent 2's utility which leads to a first-order condition

$$
\left[p_{1}-c^{\prime}\left(x\left(p_{2}\right)\right)\right] x^{\prime}\left(p_{2}\right)=0 .
$$

Since $x^{\prime}\left(p_{2}\right)<0$ under our assumptions, this implies that

$$
p_{1}-c^{\prime}\left(x\left(p_{2}\right)\right)=0
$$

Combining (5)-(7) we see that

$$
u^{\prime}\left(x\left(p_{2}\right)\right)-c^{\prime}\left(x\left(p_{2}\right)\right)=0
$$

which is the equation that characterizes the competitive equilibrium outcome. Furthermore, $p_{1}=p_{2}=u^{\prime}\left(x_{e}\right)=c^{\prime}\left(x_{e}\right)$, so the allocation of both the activity $x$ and money are exactly the same as in the competitive equilibrium.

Here is another proof that the compensation mechanism yields the competitive equilibrium as a subgame perfect equilibrium. The first step, already noted above in equation (5), is that in equilibrium $p_{1}=p_{2}$. Second, we note that agent 1 will make a utility-maximizing choice of $x^{*}$ in the second stage which means

$$
u\left(x^{*}\right)+p_{2}\left[\bar{x}-x^{*}\right] \geq u(x)+p_{2}[\bar{x}-x],
$$

for all $x$. Third, we note that by appropriate choice of $p_{2}$ agent 2 can induce agent 1 to make any choice of $x$ that he desires. Hence utility maximization by agent 2 implies

$$
-p_{1}\left[\bar{x}-x^{*}\right]-c\left(x^{*}\right) \geq-p_{1}[\bar{x}-x]-c(x),
$$

for all $x$.

Adding equations (8) and (9), and using the fact that $p_{1}=p_{2}$ we see that

$$
u\left(x^{*}\right)-c\left(x^{*}\right) \geq u(x)-c(x)
$$

for all $x$, which shows that $x^{*}$ is the Pareto efficient amount of the externality.

Note that the initial endowment of the externality, $\bar{x}$, is not involved in this argument. This means that the compensation mechanism can be used to construct either the Pigovian or the Coasian solution to the externalities problem--it all depends on the initial assignment of property rights. 


\section{Defects of the compensation mechanism}

The main defect of the compensation mechanism is that it requires full information. In order for one agent to know the correct price to announce, it is necessary that he know something about the other agent's objective function. In fact, this is what makes the mechanism work--neither agent has an information monopoly, and we are able to make them "compete" in revealing the information they have about each other's objectives.

However, there are certainly cases where obtaining such information is costly and/or difficult. It also may be easier for one party to obtain the information than for the other. For example, consider a firm that imposes pollution costs on one hundred consumers. If the firm is liable in part for the pollution costs it imposes on the consumers the firm may well have more of an incentive to investigate the magnitude of the costs it imposes on the consumers than the consumers have to investigate the costs the firm might bear in reducing pollution.

This sort of consideration seems very much in line with Coase's thinking. As he emphasizes in Coase (1988) who has the property rights is irrelevant in a world with no transactions costs, but this is an essential issue of resource allocation when transactions costs are present.

Such considerations suggest that the no-intervention initial endowment is a more plausible endowment than the hypothetical original position endowment that generates the Pigovian outcome, on the simple grounds that it is easier to contemplate how much I would pay to reduce the level of some externality starting at the status quo rather than think about how much of some externality I would allow if none were present. However, considerations like this are only suggestive; presumably each case must be handled on its own.

\section{A dynamic tatonnement}

One way to get around the full-information problem with the compensation mechanism is to think about it in terms of a tatonnement. We have shown that the compensation mechanism implements the competitive equilibrium as a subgame-perfect equilibrium; but, at least in some cases, it also leads to competitive equilibrium if the agents follow a simple and rather natural tatonnement. Furthermore, this tatonnement does not require any global information about the other agents' costs.

Specifically, let us suppose that the state of the system at time $t$ is summarized by the prices announced by each agent and the level of production of the externality, $\left(p_{1}(t), p_{2}(t), x(t)\right)$. Since agent 1 is penalized whenever it names a price that is different than that named by agent 2 , in period $t+1$ he will set $p_{1}(t+1)=p_{2}(t)$. In the choice stage, agent 1 will choose $x$ to maximize $u(x)-p_{2}(t) x$, yielding $x\left(p_{2}(t)\right)$. Finally, agent 2 will adjust $p_{2}$ in the direction that increases his utility.

Formally, we can write this dynamical system as

$$
\begin{aligned}
& p_{1}(t+1)=p_{2}(t) \\
& p_{2}(t+1)=p_{2}(t)-\gamma\left[p_{1}(t)-c^{\prime}\left(x\left(p_{2}(t)\right)\right] .\right.
\end{aligned}
$$

Here $\gamma>0$ is a speed of adjustment parameter. The differential analog of this system is

$$
\begin{aligned}
& \dot{p}_{1}=p_{2}-p_{1} \\
& \dot{p}_{2}=-\gamma\left[p_{1}-c^{\prime}\left(x\left(p_{2}\right)\right)\right] .
\end{aligned}
$$

It is easy to show that the competitive equilibrium is locally stable under this adjustment process. Hence, naive agents who follow this sort of tatonnement might reasonably be expected to converge to a competitive equilibrium.

Note that neither of the agents needs to know anything about the other agent's cost or utility. All that is necessary is that agent 2 believes that if he increases the price faced by agent 1 , the level of the externality will decrease.

In summary: sophisticated, fully-informed agents may reasonably be expected to play the subgame-perfect equilibrium. Naive, poorly-informed agents may be expected to play the tatonnement. Either model predicts the competitive equilibrium as the outcome. ${ }^{4}$

\footnotetext{
However, there is nothing to suggest that we will get a desirable outcome if, say, a sophisticated agent
plays a naive agent. But this is true of all of game theory.
} 


\section{Summary}

I have shown that the Pigovian solution to an externalities problem can be interpreted as a competitive equilibrium from an initial endowment of no production. The Coasian solution can be viewed as a competitive equilibrium from an initial endowment of no intervention. Either of these outcomes can be achieved by a mechanism that implements the competitive equilibrium.

In a world with no transactions costs there is no reason to choose between the Coasian and Pigovian treatments: both come down to finding a way to achieve an efficient allocation that Pareto dominates some initial endowment. A mechanism that solves one problem will solve the other.

I have described one such mechanism, the compensation mechanism here. This is, however, only one example among many. I think that the compensation mechanism has nice theoretical properties. The question is, how does it work in practice? I am currently carrying out a series of laboratory experiments to investigate this question.

\section{References}

Arrow, K. (1970). The organization of economic activity: Issues pertinent to the choice of market versus non-market allocation. In Haveman, R. H., and Margolis, J. (Eds.), Public Expenditures and Policy Analysis, pp. 59-73. Markham.

Baumol, W. J. (1972). On taxation and the control of externalities. American Economic Review, 62(3), 307-322.

Binmore, K., and Dasgupta, P. (1987). The Economics of Bargaining. Blackwell, Oxford England.

Coase, R. H. (1960). The problem of social cost. Journal of Law and Economics, 3, 1--44.

Coase, R. H. (1988). Notes on the problem of social cost. In Coase, R. H. (Ed.), The Firm, The Market, and the Law, pp. 157-186. The University of Chicago Press, Chicago.

Groves, T. (1979). Efficient collective choice when compensation is possible. Review of Economic Studies, 46, 227-241.

Groves, T., and Ledyard, J. (1987). Incentive compatibility since 1972. In Groves, T., Radner, R., and Reiter, S. (Eds.), Information, Incentives and Economic Mechanisms. University of Minnesota Press, Minneapolis.

Hurwicz, L. (1979). Outcome functions yielding Walrasian and Lindahl allocations at Nash equilibrium points. Review of Economic Studies, 46, 217-225.

Maskin, E. (1985). The theory of implementation in Nash equilibrium. In Hurwicz, L., Schmeidler, D., and Sonnenschein, H. (Eds.), Social Goals and Social Organization, pp. 173-204. Cambridge Univeristy Press, Cambridge.

Moore, J. (1991). Implementation in environments with complete information. Tech. rep., Suntory-Toyota International Centre for Economics, London School of Economics.

Nash, J. (1953). Two-person cooperative games. Econometrica, 21, 128-140.

Pigou, A. C. (1920). The Economics of Welfare. Macmillan, London.

Samuelson, P. A. (1963). Modern economic realities and individualism. The Texas Quarterly, Summer, 128. Reprinted in The Collected Scientific Papers of Paul A. Samuelson, volume 2, MIT Press, Cambridge, MA.

Samuelson, P. A. (1967). The monopolistic competition revolution. In Kuenne, R. E. (Ed.), Monopolistic Competition Theory: Studies in Impact; Essays in Honor of Edward $H$. Chamberlin. Wiley, New York. Reprinted in The Collected Scientific Papers of Paul A. Samuelson, volume 3, MIT Press, Cambridge, MA.

Schmeidler, D., and Vind, K. (1974). Fair net trades. Econometrica, 40, 637--642.

Schweizer, U. (1988). Externalities and the coase theorem: Hypothesis or result?. Journal of Institutional and Theoretical Economics, 144, 245-266. Reprinted in Eirik Furubotn and Rudolf Richter, The New Institutional Economics, Mohr, Tubingen, 1991. 
Schweizer, U. (1989). Calculus of consent: A game-theoretic perspective. Tech. rep., University of Bonn, Bonn, Germany. Presented at the International Seminar on the New Institutional Economics, Wallerfangen, May 31-June 2, 1989.

Tirole, J. (1988). Theory of Industrial Organization. M.I.T. Press, Cambridge, MA

Varian, H. (1989). A solution to the problem of externalities when agents are wellinformed. Tech. rep., CREST Working Paper.

Walker, M. (1981). A simple incentive compatible scheme for attaining Lindahl allocations. Econometrica, 48, 56-73. 